\title{
Development of Convection Along the SPCZ Within a Madden-Julian Oscillation
}

\author{
By ADRIAN. J. MATTHEWS ${ }^{1 *}$ BRIAN. J. HOSKINS ${ }^{1}$ JULIA. M. SLINGO ${ }^{1}$ and MIKE \\ BLACKBURN $^{1}$ \\ ${ }^{1}$ University of Reading, UK
}

(Received 17 May 1995; revised 21 September 1995)

Summary

A subtropical Rossby wave propagation mechanism is proposed to account for the poleward and eastward progression of intraseasonal convective anomalies along the South Pacific Convergence Zone (SPCZ) that is observed in a significant proportion of Madden-Julian Oscillations (MJOs). Large scale convection, associated with an MJO, is assumed to be already established over the Indonesian region. The latent heating associated with this convection forces an equatorial Rossby wave response with an upper tropospheric anticyclone, centred over or slightly to the west of the convection. Large potential vorticity (PV) gradients, associated with the subtropical jet and the tropopause, lie just poleward of the anticyclone and large magnitude PV air is advected equatorwards on the eastern side of the anticyclone. This "high" PV air, or upper tropospheric trough, is far enough off the equator that it has associated strong horizontal temperature gradients, and it induces deep ascent on its eastern side, at a latitude of about $15-30^{\circ}$. If this deep ascent is over a region susceptible to deep convection, such as the SPCZ region, then convection may be forced or triggered. Hence convection develops along the SPCZ as a forced response to convection over Indonesia. The response mechanism is essentially one of subtropical Rossby wave propagation. This hypothesis is based on a case study of a particularly strong MJO in early 1988, and is tested by idealised modelling studies. The mechanism may also be relevant to the existence of the mean SPCZ, as a forced response to mean Indonesian convection.

KEYwords: Equatorial Rossby waves Madden-Julian oscillation Potential vorticity South Pacific convergence zone Tropical convective anomalies

\section{INTRODUCTION}

The Madden-Julian Oscillation (MJO), or intraseasonal oscillation, has been well established as a fundamental mode of tropical atmospheric variability. Composite studies, such as those of Knutson and Weickmann (1987) and Rui and Wang (1990), have characterised the tropical MJO as an eastward propagation of planetary scale convective and circulation anomalies around the globe with a time scale of between 30 and 60 days. The tropical convective anomalies are strongest over the warm pool of the Indian Ocean, the maritime continent, and the West Pacific; they are mainly absent over the cooler waters of the East Pacific, and rather weak over the Amazon basin and central Africa. There is a tendency for a dipole structure to the convective anomalies, with enhanced convection over the Indian Ocean coincident with reduced convection over the West Pacific. Coherent tropical circulation anomalies are associated with the convective anomalies. A pair of upper tropospheric anomalous anticyclones are either coincident or slightly to the west of the positive convective anomaly. The circulation in the lower troposphere is of the opposite sign, with cyclonic anomalies below anticyclonic anomalies.

Although compositing techniques reveal the large scale, low frequency part of the MJO very well, they do have shortcomings. Any higher frequency component of the MJO will be filtered out, both by the actual low pass filtering of the data that is usually employed, and also by the compositing procedure itself; unless a certain high frequency component occurred at exactly the same phase of each oscillation, it would be averaged out during the compositing. As the timescale of the oscillation varies by a factor of two,

* Corresponding author: Dept. of Meteorology, University of Reading, 2 Earley Gate, Whiteknights, PO Box 239, Reading, Berkshire RG6 6AU, UK 
between 30 and 60 days, such an exact phase relationship between the high and low frequency components of the MJO would seem unlikely.

A second, and more directly relevant, shortcoming of the compositing techniques is that they will tend to merge together different variants of the same phenomenon. Apart from the seasonal differences in the oscillation (e.g. Knutson and Weickmann 1987; Matthews 1993), there are other significant variants on the basic eastward propagating MJO. Wang and Rui (1990) classified ten years of MJOs according to the propagation characteristics of their convective anomalies. They distinguished between modes that predominantly propagated along the equator from the Indian Ocean into the Pacific, and modes that propagated eastward to Indonesia, but then developed in a poleward and eastward direction. However, their "equatorial" mode also showed some development in a poleward and eastward direction, making a clear distinction between different types of behaviour difficult. In southern summer, the poleward and eastward development of intraseasonal convective anomalies was almost exclusively in a southeastward direction, in the region of the South Pacific Convergence Zone (SPCZ).

The SPCZ is a semi-permanent feature of the southern hemisphere tropical and subtropical atmosphere. It is strongest in southern summer, and is characterised by a band of cloud extending in a NW-SE direction from around New Guinea into the South Pacific. Other fields also show an SPCZ structure. There appears to be no universally accepted theory for the NW-SE alignment of the SPCZ (Vincent 1994). Although the NW-SE alignment of the axis of maximum SST may immediately suggest such a theory, this is not verified by modelling studies. In a GCM experiment, Kiladis et al (1989) removed South America and the cool SSTs of the East Pacific and imposed a zonal SST structure over the whole of the Pacific and Atlantic region. The simulated SPCZ still retained its NW-SE alignment even in the absence of any similarly orientated SST distribution. They suggested that the NW-SE alignment of the SPCZ reflected a "storm track" with the tropical convergence zone interacting with transient troughs in the midlatitude westerlies. The MJO is known to strongly affect the SPCZ. Weickmann et al (1985) found that intraseasonal OLR anomalies propagated eastward from the Indian Ocean through to the West and Central Pacific in southern summer, but their behaviour around the SPCZ region was rather confusing.

Theoretical work on the MJO has tended to concentrate on the equatorial, eastward propagating part of the oscillation. This has been interpreted in terms of moist Kelvin waves (e.g. Lau and Peng 1987) and a feedback involving evaporation (Emanuel 1987; Neelin et al 1987) to varying degrees of success. Mechanisms have also been proposed for the northward propagating intraseasonal oscillations over India and southeast Asia during the summer monsoon; Webster (1983) simulated a northward propagation over southeast Asia in a simple model when land-surface processes were allowed to interact with dynamics. However, the mechanisms for the poleward and eastward propagating parts of the MJO appear not to have been discussed.

This paper describes a case study of a particularly strong MJO that occurred in March-April 1988. A hypothesis, based on the observations, is developed to explain the southeastward development of the convection from Indonesia down the SPCZ. An idealised model is then used to test this hypothesis. Section 2 describes the data used in the case study, which is itself presented in section 3 . The idealised modelling study is described in sections 4 and 5, and a summary and discussion are presented in section 6 .

\section{DATA}


Initialised analyses of the global atmosphere from the European Centre for Medium Range Weather Forecasts (ECMWF) are used to study the MJO of March-April 1988. The data are retrieved as spectral coefficients of vorticity, divergence, temperature and surface pressure at triangular truncation 42 and at 19 levels in the vertical. Daily averages are constructed from the six-hourly analyses. A description of the analysis procedure at ECMWF can be found in Hoskins et al (1989). Importantly, over the period of interest, the analysed tropical divergent wind field is realistic, in that it agrees well with an essentially independent estimate of the divergent wind calculated from analysed vorticity, using the vorticity equation. OLR is also used in this study as a proxy for deep convection in the tropics. OLR effectively measures cloud top temperature; hence regions of deep convection (and associated upper tropospheric divergence and mid-tropospheric ascent) are strongly anticorrelated with OLR measurements (Ardanuy and Arkin 1989). However, high cirrus cloud is also associated with low OLR values, even though there may be no deep convection in the area. The OLR is obtained from the NOAA Advanced Very High Resolution Radiometer (AVHRR) as daily data on a $2.5^{\circ}$ latitude-longitude grid (for details see Ju and Slingo 1995). Missing values have been filled by linear interpolation.

\section{Case Study of the March-April 1988 MJO}

Matthews (1993) noted that the MJO event of March-April 1988 was the strongest event in the 1982-90 period, in terms of coherent eastward propagating circulation features. The maximum zonal wind anomaly was about $17 \mathrm{~m} \mathrm{~s}^{-1}$. This particular event has also been noted in terms of its strong atmospheric angular momentum anomaly and length-of-day signal (Nastula it et al 1990); i.e. the zonal mean part of the MJO is strong too. In fact, the MJO of March-April 1988 is strong enough to be seen in raw, daily data, and it is unnecessary to time filter the data, or to take anomalies from climatology. However, for reasons of compactness and to document the large scale, low frequency part of the MJO, pentad mean OLR and streamfunction on the $355 \mathrm{~K}$ isentropic surface are first shown in Fig. 1. The 355K surface is close to the $150 \mathrm{mb}$ level at all latitudes. It is in the upper troposphere in the tropics, and the lower stratosphere in middle latitudes. The 45 days covered show the whole of this particular MJO, and dates below refer to the middle of the pentad.

- 7 March. Convection is strong and organised over the SPCZ, South America and Africa, but relatively weak over the Indian Ocean through to the West Pacific. There are weak equatorial upper tropospheric westerlies over the Indian Ocean.

- 12 March. There is now some convection over the Indian Ocean, and the upper tropospheric westerlies there have been replaced by easterlies. Convection has disappeared from the SPCZ.

- 17 March. Convection is becoming organised over the Indian Ocean and Indonesia.

- 22 March. Convection is strengthening over the east Indian Ocean and Indonesia, and now developing down the SPCZ. There is an associated strong upper tropospheric anticyclone pair together with equatorial easterlies from Africa to the West Pacific. Convection is reduced over South America.

- 27 March. Convection peaks over Indonesia, and strengthens over the SPCZ. Over South America and Africa there is little deep convection; in fact there are now upper tropospheric equatorial westerlies over South America and the Atlantic.

- 1 April. Convection is decaying over Indonesia, and strengthening over the SPCZ. There are weak upper tropospheric westerlies over the Indian Ocean. 
- 6 April. Convection has almost disappeared from over Indonesia, and peaks over the SPCZ.

- 11 April. Convection is now weakening over the SPCZ.

- 16 April. There is now little organised convection anywhere in the tropics, but convection is regaining strength over South America and the equatorial Atlantic.

The overall feature of the MJO is characterised by the eastward propagation of a mainly zonal wavenumber 1 convective envelope, with maximum amplitude over the Indian Ocean, Indonesia and the West Pacific region. There is substantial convection along the SPCZ, but, rather than developing eastward and then propagating purely down the SPCZ, the convection over the Pacific appears to consist of both an equatorial part together with a NW-SE oriented SPCZ part; this whole structure then moves eastward, over the 5 pentads from 22 March to 11 April. The upper tropospheric ridge-trough structure that is characteristic of the SPCZ also moves eastward over this period.

Attention is now focused on just one period of this MJO, that when convection is already well established over Indonesia, and is developing down the SPCZ. Other aspects of the MJO, such as the primary initiation of convection in the Indian Ocean, and the zonal mean part of the oscillation, will be addressed elsewhere. Daily mean fields of OLR and $355 \mathrm{~K}$ streamfunction, and $355 \mathrm{~K}$ potential vorticity $(\mathrm{PV})$ together with vertical velocity in pressure coordinates (omega) at $500 \mathrm{mb}$, are shown from 26 March to 31 March in Fig. 2. The PV indicates the position of the $355 \mathrm{~K}$ surface with respect to the tropopause; the values below $1 \mathrm{PVU}$ in the tropics are indicative of the troposphere, and the higher values in the subtropics correspond to stratospheric air.

- 26 and 27 March. There is large scale, organised convection over the Indonesian region. The tropical upper tropospheric flow shows an almost symmetric pair of anticyclones associated with the convection. The subtropical jets are relatively zonal up to about $150^{\circ} \mathrm{E}$ (note especially the southern hemisphere jet), in terms of wind direction and $\mathrm{PV}$. The NW-SE aligned ridge-trough structure of the SPCZ is clearly evident on this day and every other day. Associated with the convection and latent heat release over Indonesia, there is a large-scale region with mostly ascent in the middle troposphere; the SPCZ also has some convection and associated ascent.

- 28 March. The convection over Indonesia is extending southwards over Australia and eastwards into the West Pacific. The upper tropospheric anticyclone in the southern hemisphere is advecting "high" (negative) PV air equatorwards to the east of the convection. Outside of the convecting regions (regions of low OLR), PV will be approximately materially conserved over the timescale of a few days that is considered here.

- 29 March. There is now a strong upper tropospheric trough, or equatorward incursion of high $\mathrm{PV}$ air, at $160^{\circ} \mathrm{E}$, to the east of the Indonesian convection and upper anticyclone, such that strong upper level westerlies have penetrated as far equatorward as $8^{\circ} \mathrm{S}$. The trough, in a region of westerly vertical shear, may be associated by omega equation arguments with the ascent to the east at $20^{\circ} \mathrm{S}, 170^{\circ} \mathrm{E}$ and the descent to the west at $30^{\circ} \mathrm{S}, 160^{\circ} \mathrm{E}$ (not shown). This ascent region to the east is over the SPCZ, which by now has substantial convection. Figure 3 shows a vertical section of omega at $170^{\circ} \mathrm{E}$. The ascent at around $20^{\circ} \mathrm{S}$ is indeed deep, extending throughout the whole troposphere. In the deep convective heating region over Indonesia-Australia, there is a large region of positive $\mathrm{PV}$ in the southern hemisphere (at around $10^{\circ} \mathrm{S}$ ) at $355 \mathrm{~K}$ (not shown), associated with the strong upper tropospheric anticyclone.

- 30 and 31 March. A tongue of large negative PV is being advected from the east side of the anticyclone around to the equatorward side. This "high" PV air, with its implied 
strong stratification, is coincident with a lack of convection (high OLR) and appears to divide the Indonesian-Australian convection into two regions, one to the north near the equator and one to the south near Australia.

A hypothesis for the development of the convection along the SPCZ, developed in the light of the observations described above, is shown in schematic form in Fig. 4. Large scale convection is established over the Indonesian region by the passage of an MJO (1). The latent heat release associated with the convection forces an equatorial Rossby response, with an upper tropospheric anticyclone over Indonesia-Australia, centred only slightly to the west of the heating (2). There is a large PV gradient, associated with the tropopause and the subtropical jet, just poleward of the anticyclone (3). To the east of the Indonesian convection, high magnitude PV air is advected equatorward by the anticyclone (4). This "high" PV air, or upper tropospheric trough has associated vertical shear and horizontal temperature gradients, and induces deep ascent on its eastern side (5), to the southeast of the convection over Indonesia. Since this induced deep ascent is over the SPCZ, a region of high SSTs and ambient low level moisture convergence which is susceptible to deep convection, strongly enhanced convection is likely to be triggered. Hence convection develops along the SPCZ, as a response to the convection over Indonesia (6).

This subtropical Rossby wave propagation mechanism is hypothesised to account for the southeastward development of the MJO over the West Pacific. A similar mechanism may account for the northeastward development that mainly occurs in northern summer. However, with the diagnostic approach it cannot be determined whether the deep ascent over the SPCZ region is forced by the upper tropospheric trough, and convection is then triggered by this ascent as hypothesised above, or whether the convection over the SPCZ arose by some other means, and the deep ascent there is a response to that convection. A prognostic approach is needed to distinguish between these two scenarios. The next section describes a series of idealised modelling experiments designed to test the above hypothesis.

The effect of the tongue of "high" PV air that is advected around the anticyclone may also be important. As noted above, it coincides with suppressed convection, which may be due to the high static stability associated with the large values of PV. This "high" PV tongue, the suppression of convection, and the splitting of the Indonesian convective complex in two, may be a common factor to the MJOs that show significant development of convection along the SPCZ. This tentative suggestion does not appear to be crucial to the main hypothesis, but certainly merits further investigation.

\section{Idealised Modelling Study}

An idealised numerical model is used to test the subtropical Rossby wave hypothesis of the previous section. The model is the global, spectral transform, primitive equation model of Hoskins and Simmons (1975) that has been used for a wide range of experiments. It is run at triangular truncation 42 resolution, with 24 levels in the vertical. There is high vertical resolution near the tropopause to accurately resolve PV at this level. All processes that are not fundamental to the hypothesis being tested are excluded from the model; there is no orography, damping or drag, and no diabatic processes, apart from the idealised heating described below, and $\nabla^{6}$ hyperdiffusion that acts with a timescale of 4 hours on the smallest resolvable scale.

The presence of the subtropical jet and its associated large PV gradients is considered crucial, hence the initial state is a climatological March-April-May (MAM) flow (Fig. 5), 
taken from 6 years (1983-89) of ECMWF analyses (Hoskins et al 1989). This basic state is not a steady state solution of the governing equations, so it is balanced by a constant forcing term, which represents the effect of radiation, boundary layer and moist processes, transients and other processes not explicitly included in the model, in maintaining the climatological mean state. While this technique has been used in many previous studies (e.g. Jin and Hoskins 1995) and produced realistic results, it must be noted that the real basis for these assumptions is questionable.

The starting point for the hypothesis is the presence of convective heating over Indonesia. This is represented by an idealised elliptical heat source with a cosine squared profile, centred at $10^{\circ} \mathrm{S}, 130^{\circ} \mathrm{E}$, which is shown in Fig. 6 together with the OLR field on 28 March. The idealised heat source has a vertical structure close to that of observed deep tropical cumulonimbus clouds, peaking at $400 \mathrm{mb}$ and decreasing to zero by 250 mb. This heating, with a column average value of $2.5^{\circ} \mathrm{C}$ day ${ }^{-1}$, is held fixed as the model is integrated forward in time. The direct response to the idealised heating can then be followed over the first few days. The initial basic state is actually baroclinically unstable, but, as in Jin and Hoskins (1995), baroclinic waves remain at negligible amplitude for at least the first ten days of the integration, by which time the direct response to the idealised heating is well established.

Kelvin and Rossby wavefronts propagate eastward and westward, respectively, in a response to the sudden switching on of the heating. These wavefronts are similar to those in the model of Heckley and Gill (1984), which considered a single vertical mode in a resting atmosphere. However, the vertical heating function used here excites several of the model's vertical modes. Hence, at any particular time, the atmosphere at a particular point on the equator to the east of the heating region can be considered to have adjusted to the heating via the Kelvin modes that have passed through that point, but to be unadjusted via the higher vertical wavenumber Kelvin modes that have not yet passed that point (Fig. 7). However, as the vertical structure of the heating mainly excites the lower vertical modes (in particular the first internal tropospheric mode with circulations of opposite sign in the upper and lower troposphere), the whole of the Pacific region is essentially fully adjusted via Kelvin waves to the imposed heating by about day 3 .

Figure 8 shows the upper and lower tropospheric perturbation flow on day 3 of the integration. The Kelvin adjustment to the east (upper tropospheric westerlies and lower tropospheric easterlies), and the Rossby adjustment above and to the west (upper tropospheric anticyclones and lower tropospheric cyclones), are both evident, especially in the lower troposphere. However, the upper tropospheric tropical response also contains a strong divergent component above the heating. This is discussed later.

As anticipated, because of the non-resting basic state, there is more to the flow than just the tropical response. A cyclonic anomaly, or upper level trough, is evident to the east of the upper tropospheric anticyclone in the southern hemisphere. This upper tropospheric trough is seen more clearly using potential vorticity. The total PV field at $355 \mathrm{~K}$ on day 3 (Fig. 9a) shows a distinct trough, or equatorward incursion of "high" PV, to the east of the imposed heating. Inspection of the wind fields and PV on the $355 \mathrm{~K}$ surface for each day shows that this PV trough is a result of advection by equatorward winds on the eastern flank of the upper tropospheric anticyclone. Figure $9 \mathrm{~b}$ shows perturbation mid-tropospheric omega on day 3 . The adiabatic cooling associated with the large scale perturbation ascent over Indonesia and northern Australia balances the imposed heating and can be thought of as part of the Gill-type response. The region of weaker ascent to the southeast, around $25^{\circ} \mathrm{S}, 170^{\circ} \mathrm{E}$, is induced by the upper level trough by poleward flow along isentropes that slope upwards towards the pole. This induced ascent is deep and fills the whole troposphere from the boundary layer up to the tropopause (Fig. 9c; 
the ascent-descent structure at the equator is due to the passage of a particular vertical Kelvin mode wavefront through that longitude at that time). There are also regions of descent on the poleward and westward flanks of the upper tropospheric anticyclone (Fig. $9 \mathrm{~b})$. These can be interpreted in terms of an interaction between the equatorial Rossby modes and the subtropical jet (Rodwell and Hoskins 1996), but no further discussion is offered here.

A crucial component of the hypothesis is that the upper tropospheric anticyclone is centred approximately above the convective heating over Indonesia. This configuration will lead to equatorward advection of "high" PV air, and subsequent deep convection, to the southeast of the Indonesian convection. If the upper tropospheric anticyclone were located to the west of the convective heating over Indonesia, such a scenario would be impossible. In a resting atmosphere, the equatorial Rossby wave response is such that the upper tropospheric anticyclone is centred to the west of the heating, as part of a Sverdrup vorticity balance, where vortex compression above the heating is balanced by advection of planetary vorticity by the equatorward flow on the eastern flank of the upper tropospheric anticyclones (Gill 1980; Heckley and Gill 1984). However, in a non-resting atmosphere, the upper tropospheric anticyclone can be centred above the heating (Jin and Hoskins 1995). Over Indonesia, the basic state has a region of almost zero absolute vorticity, and therefore zero meridional vorticity gradients, due to the mean convection over Indonesia. Hence, the forced equatorial Rossby wave does not propagate westward very effectively.

This region of almost zero vorticity and vorticity gradient in the upper troposphere above Indonesia could also explain the strong $150 \mathrm{mb}$ divergent flow over the prescribed Indonesian heating noted above (Fig. 8a). The region of almost zero vorticity over Indonesia at around $150 \mathrm{mb}$ is present from the start of the integration as part of the climatological basic state. Vortex compression above the prescribed Indonesian heating will then tend to further decrease and homogenise the vorticity field. The effect of the almost zero vorticity region is to weaken the rotational constraint on the flow, and to allow a simple Hadley circulation with divergence and poleward flow above the Indonesian heating. Below this level, by about $250 \mathrm{mb}$, there is a significant meridional vorticity gradient; the rotational constraint returns, and the response is much more like that of an equatorial Rossby wave, with weakened divergent, Hadley circulation.

There are other similarities between the model response and the observed MJO. There is a region of (weak) positive $\mathrm{PV}$ in the southern hemisphere, above and to the west of the heating region (Fig. 9a). Compression of the vertical component of vortex lines can, and does, decrease the magnitude of $\mathrm{PV}$ as described above, but it cannot change its sign. However, such a change in sign can arise from the contributions to the $\mathrm{PV}$ tendency from the horizontal components of vorticity and diabatic heating gradients. A scale analysis of these terms shows that they are of the right sign and magnitude to produce positive $\mathrm{PV}$ in the heating region within a few days. This positive $\mathrm{PV}$ air is then advected upwards and westwards (to around $5^{\circ} \mathrm{S}, 105^{\circ} \mathrm{E}$ in Fig. 9a) by the flow associated with the equatorial Rossby wave response to the heating.

Elsewhere within the heating region, upper tropospheric PV magnitudes have been reduced from their initial values, with the effect that the large magnitude (negative) PV contours have receded polewards over Australia. By day 5, the tongue of "high" PV in the trough has been advected further equatorwards and westwards along the equatorial flank of the southern hemisphere anticyclone.

The model, therefore, appears to have been successful in simulating those parts of the MJO which form part of the hypothesis based on the case study. Convective heating over Indonesia forces an anticyclone in the upper troposphere above Australia. This 
anticyclone advects high PV air equatorwards on its eastern flank. The high PV air, or upper level trough, then induces deep ascent at around $25^{\circ} \mathrm{S}, 170^{\circ} \mathrm{E}$. Hence cause and effect has been established, and the ascent to the southeast of the Indonesian convection can be seen as a direct effect of the existence of that convection. The next deductive step in the hypothesis, that the induced deep ascent around $25^{\circ} \mathrm{S}, 170^{\circ} \mathrm{E}$ leads to deep convection in that region, is outside the scope of this simple modelling study, and must remain speculative until further work is carried out.

Kodama (1993) found two necessary conditions for active subtropical convergence zones, of which the SPCZ is one example. One condition is that there is a low level poleward component to the flow, into or along the SPCZ, to maintain the moisture flux into the SPCZ which tends to destabilise it by differential advection of equivalent potential temperature. Moist convection within the SPCZ then maintains a moist neutral profile there. Examination of the $850 \mathrm{mb}$ winds for the pentads shown in Fig. 1 reveals a strong northwesterly flow along the band of SPCZ convection for those pentads when the SPCZ is active, (e.g. 6 April 1988) in agreement with this condition. The idealised model also appears to be consistent with this condition, in that the forced response to the heating over Indonesia also shows a (weak) poleward component to the low level flow (Fig. 8b) from around $15^{\circ} \mathrm{S}$ to $40^{\circ} \mathrm{S}$ at the longitude of the forced "SPCZ" ascent region $\left(170^{\circ} \mathrm{E}\right)$. This poleward flow is part of the equivalent barotropic Rossby wave response that fills the whole troposphere in the southern hemisphere subtropics, and is associated with the ascent along sloping isentropes (Fig. 9c). Hence the direct response at low levels to the southeast of the Indonesian heating would be in the correct sense (poleward flow) to maintain the moisture flux into the SPCZ, and to destabilise it by differential advection of equivalent potential temperature. However, as moisture and convective processes are not explicitly represented in this idealised model, the next deductive step, the onset of convection over the SPCZ, must still remain speculative as noted above. The other necessary condition for an active SPCZ (Kodama 1993) is the close proximity of a subtropical jet, at around $30-35^{\circ}$. The necessary existence of the subtropical jet clearly fits with the mechanism hypothesised here, and the importance of its location is investigated in the next section.

\section{Sensitivity Tests}

It now remains to check the robustness of these model results to small changes in the experimental setup. Integrations were performed to assess the importance of nonlinearity, the initial climatological state, and the position and shape of the heating function. Comparisons were then made with the results of the "control" integration described above.

A linear integration with the heating at infinitesimally small amplitude was carried out, in order to assess the importance of the non-linear advection terms and modification of the basic state in the control integration. Both the qualitative and quantitative nature (once the response has been appropriately rescaled) of the relevant parts of the response remained effectively unchanged, with the induced ascent to the southeast of the Indonesian convection being similar to that in the fully non-linear integration, in terms of position and magnitude. However, there were some other differences.

There was a change in the divergent outflow level above the heating. In the full nonlinear experiment, the diabatic heating warmed the atmosphere below $250 \mathrm{mb}$, whilst ascent adiabatically cooled the atmosphere above $250 \mathrm{mb}$. This destabilisation eventually lead to a neutral upper troposphere. With zero vertical potential temperature gradient, 
there was then no thermodynamical constraint on vertical velocity in the upper troposphere, and ascent continued right up to the (sharpened) tropopause at around $120 \mathrm{mb}$. Initially, the linear experiment developed in a similar manner to the nonlinear experiment. The diabatic heating sets up a "primary" circulation with ascent extending above the top of the heating region (at $250 \mathrm{mb}$ ) right up to the tropopause. As in the nonlinear integration, this ascent tended to adiabatically cool the upper troposphere. However, in the linear experiment, the vertical temperature profile (and hence static stability) was effectively kept constant, hence a neutral layer could not develop in the upper troposphere. Instead, after a few hours, relatively cold air above the diabatic heating set up a "secondary" circulation with descent that exactly balanced the ascent in the "primary" circulation. There was then zero vertical velocity above the heating region, and the divergent outflow was very close to $250 \mathrm{mb}$. This rather significant change in the local dynamics of the heating region does not appear to significantly affect the downstream trough and subsequent ascent ahead of it.

Initially, the nonlinear and linear integrations are also rather similar outside of the heating region. In the linear integration, the basic state does not change and there is downstream development of a stationary Rossby wave train, consistent with the findings of Hoskins and Karoly (1981). The upper tropospheric trough to the southeast of the Indonesian heating is just part of this Rossby wavetrain. In the nonlinear integration, the basic state is changed (by the Rossby wavetrain amongst other systems), and the Rossby wavetrain is not stationary. In fact there is a slow eastward movement of the wavetrain at $150 \mathrm{mb}$, such that by day 10 there is equatorward flow at $150 \mathrm{mb}$ and $30^{\circ} \mathrm{S}, 170^{\circ} \mathrm{E}$. However, the Rossby wavetrain has now changed from an equivalent barotropic structure in the upper troposphere to one with an eastward tilt with height, such that there is still poleward flow and ascent at $500 \mathrm{mb}$ and $30^{\circ} \mathrm{S}$. With the heating magnitude used here, these nonlinear effects become important at about day 4 .

If the heating is moved $10^{\circ}$ northwards to be centred on the equator, then the ascent over the SPCZ region in a nonlinear integration is similar to that when the heating is centred at $10^{\circ} \mathrm{S}$, as in the control experiment. However, the ascent takes a few days longer to become established, only attaining an amplitude of $-1 \mathrm{mb} \mathrm{hr}^{-1}$ on day 5 , compared with day 3 in the control. In a linear integration, with the heating centred on the equator, the ascent over the SPCZ region remains very weak throughout the whole integration. This can be interpreted in terms of the relative positions of the heating and the large PV gradients associated with the subtropical jet. In the linear integrations, these large PV gradients are fixed for all time, at around $30^{\circ} \mathrm{S}$. With heating on the equator, the distance between the heating and the large PV gradients is too far (more than the meridional scale of the upper tropospheric anticyclone, about $25^{\circ}$ or two equatorial Rossby radii) for there to be a significant interaction between the heating and the large PV gradients, and there is little ascent over the SPCZ region. In the nonlinear integration, "high" PV air and large PV gradients are eventually advected equatorwards on the eastern flank of the upper tropospheric anticyclone, such that by about day 5 the large PV gradients are at about $25^{\circ} \mathrm{S}$, which appears to be close enough to the equatorial heating so that significant ascent can occur over the SPCZ region.

This dependence on the nonlinear equatorward advection of PV could have relevance to the development characteristics of individual MJOs. If the latent heating associated with a particular MJO as it passed over Indonesia was over the equator, that equatorial heating may have to be of a particular minimum strength, and may have to remain over Indonesia for a particular minimum time, in order to advect large PV gradients far enough equatorwards to then force significant ascent over the SPCZ region. If this happened, the MJO may then tend to develop along the SPCZ. If, however, the equatorial 
MJO convection was too weak or was propagating eastwards too fast, then it may not force significant ascent over the SPCZ region, and may continue propagating eastwards along the equator. If the latent heating over Indonesia associated with the MJO was positioned off the equator, at around $10^{\circ} \mathrm{S}$, then it appears to be close enough to the large PV gradients anyway, and the initial nonlinear equatorward advection of large PV gradients is unnecessary to force significant ascent over the SPCZ region.

It is the relative distance between the heating and the large PV gradients that appears to be important; it must be at most about two equatorial Rossby radii. Hence, if the large PV gradients were displaced equatorwards by another system, e.g. the passage of a mid-latitude baroclinic wave or low frequency variability not associated with the $\mathrm{MJO}$, then convection on the equator may immediately be able to force significant ascent over the SPCZ region, and not have to first advect large PV gradients equatorwards. Conversely, if the large PV gradients were somehow displaced polewards from their mean position, then the ascent over the SPCZ region may be reduced, even if the heating was at $10^{\circ} \mathrm{S}$.

To test this hypothesis, and to also assess the importance of zonal asymmetries in the basic state, another integration was performed, using the zonally averaged March-AprilMay climatology as the initial state, rather than the full three dimensional field. Again, the response was qualitatively similar to the control experiment, but there were some interesting differences. The upper tropospheric trough and its induced ascent were weaker in the zonally averaged experiment, but the PV tongue that was advected westward around the equatorward flank of the anticyclone was much stronger and more coherent (Fig. 10). As anticipated, this can be explained by differences in the meridional PV gradient between the two experiments. The subtropical jet over Australia is strong, compared to the zonal mean at that latitude (Fig. 5), and there is therefore a stronger meridional PV gradient across the jet, and a weaker meridional PV gradient equatorward of the jet, as compared to the zonal mean. The upper tropospheric trough and its induced ascent are approximately at the same latitude as the jet, and are therefore stronger using the zonally asymmetric basic state, than with the zonal mean basic state. Conversely, the $\mathrm{PV}$ tongue that is advected around the equatorward flank of the anticyclone is from the equatorward side of the jet, and is therefore weaker using the zonally asymmetric basic state, than with the zonal mean basic state.

The zonally asymmetric basic state already contains an SPCZ structure, while the zonal mean state does not. As the basic response was similar in both the experiments, the existence or absence of an initial SPCZ structure does not appear to be crucial to the development of the ascent. In a further, rather trivial, experiment, the climatological basic state was removed altogether and the heating was superimposed onto a resting atmosphere. The response was entirely one of equatorial Kelvin and Rossby adjustment, with no upper tropospheric trough and subtropical Rossby wave propagation.

The response could also be sensitive to the shape of the heating function, as well as its position. To establish the effect of both of these parameters, an integration was performed with the heating function shown in Fig. 11a, representative of the OLR field on 26 March. This elliptical heating region is centred at $5^{\circ} \mathrm{S}, 120^{\circ} \mathrm{E}$, to the northwest of that of the control integration, and is elongated longitudinally. The upper level trough and induced ascent on day 3 can be seen in Fig. 11b,c. Again, the response is qualitatively very similar to that of the control integration, but the trough and ascent region are elongated longitudinally, mirroring the change in the forcing. The forced ascent over the SPCZ region, if the hypothesis is correct, would be an integrated response to the (timedependent) latent heating over Indonesia over the previous few days. Hence a response that is relatively insensitive to the exact position and shape of the heating is highly 
desirable. This experiment, with the modified heating function, was repeated for the linear case, and with the zonally averaged basic state. Results were qualitatively similar to those described for the equivalent experiments with the "control" heating function.

A possible explanation for the equatorial eastward propagating part of the MJO has been made in terms of moist Kelvin waves (e.g. Lau and Peng 1987). With a CISK type parametrization of deep convective heating, the phase speed of these moist Kelvin waves has been found to be sensitive to the vertical structure of the heating. Although the hypothesis here does not rely on Kelvin waves, another experiment was performed where the vertical structure of the heating function was changed, such that it peaked at $600 \mathrm{mb}$, rather than at $400 \mathrm{mb}$. Although the Kelvin wave response over the equatorial Pacific was slightly different, the subtropical response was very similar to that of the control integration.

Although a comprehensive investigation of parameter space has not been undertaken, the selected sensitivity experiments described above do cover the most immediate and relevant variations on the control integration. In all the integrations, the basic character of the upper tropospheric trough and induced deep ascent to the southeast of the Indonesian convection was reproduced in terms of its position and structure, indicating that this mechanism is robust to reasonable changes in external conditions. However, the actual magnitude of the subtropical response was dependent on the latitude of the heating, and on the basic state. The strongest response was obtained when the distance between the heating and the large PV gradients associated with the subtropical jet was at most the meridional scale of the upper tropospheric anticyclone, i.e. they were close enough together that they could interact significantly. Such a tendency indicates that there may be a certain amount of (medium range) predictability of a particular MJO, once it has reached Indonesian longitudes.

\section{Summary and Discussion}

A mechanism has been proposed to account for the poleward and eastward propagation of convective anomalies that is observed in many Madden-Julian Oscillations. The hypothesis behind this mechanism was based upon a case study of the particularly strong MJO of March-April 1988. In this particular MJO, convection developed from Indonesia in a southeastward direction along the South Pacific Convergence Zone (SPCZ). The Indonesian convection was accompanied by an upper tropospheric anticyclone. A strong upper tropospheric trough, or high PV anomaly, lay to the east of this upper anticyclone. To the east of this upper level trough, at around $20^{\circ} \mathrm{S}, 170^{\circ} \mathrm{E}$, deep ascent and convection (over the SPCZ) coincided. The following hypothesis has been proposed to attempt to explain this sequence of events.

Large scale convection, associated with an MJO, is assumed to be already established over the Indonesian region. The latent heating associated with this convection forces a Gill-type upper tropospheric anticyclone (equatorial Rossby wave response). Large potential vorticity (PV) gradients, associated with the subtropical jet and the tropopause, lie just poleward of the anticyclone and "high" PV air is advected equatorwards on the eastern side of the anticyclone. This "high" PV air, or upper tropospheric trough, is in a region of strong horizontal temperature gradients, and induces deep ascent on its eastern side, at a latitude of about 20-25/degr. If this deep ascent is over a region of warm SSTs, or boundary layer moisture convergence, as in the SPCZ region, then convection may be forced or triggered. Hence convection develops along the SPCZ as a forced response to convection over Indonesia. The response mechanism is essentially one of subtropical Rossby wave propagation. 
The case study was purely diagnostic and, as such, cause and effect cannot be attributed. In particular, the convection over the SPCZ may not be a forced response to the Indonesian convection, but may have arisen by other means, and the ascent over the SPCZ region would then be a response to that convection. An idealised atmospheric model is therefore used to try to establish cause and effect. The model only includes the basic dynamical and thermodynamical equations, together with the factors that are considered essential to the hypothesis, i.e., a climatological basic state with a realistic subtropical jet and associated strong PV gradients, and a representation of the latent heat release associated with the Indonesian convection. When both of these ingredients are included, the model response to the heating is one of equatorial Kelvin and Rossby adjustment in the tropics, and a subtropical response that agrees well with the hypothesis. The upper tropospheric anticyclone above the prescribed Indonesian heating advects "high" PV air equatorward on its eastern flank. This upper level trough then induces ascent at around $20-25^{\circ} \mathrm{S}, 170^{\circ} \mathrm{E}$, in the region of the $\mathrm{SPCZ}$.

The mechanism outlined above is postulated to account for the poleward and eastward propagation of intraseasonal convective anomalies, and appears to be relevant not only to the case study described here, but also to the "average" southern summer MJO, as depicted by composite studies. Knutson and Weickmann (1987) and Weickmann et al (1985) both show simultaneous development of convection over the equatorial Indonesian region and the SPCZ region. The convection along the SPCZ is seen to develop ahead of an upper tropospheric trough, consistent with the mechanism proposed here. In northern summer, intraseasonal modulation of the SPCZ tends to be of a much smaller amplitude, as the convection has switched to the northern hemisphere.

The composite studies have shown that modulation of the SPCZ happens in an "average" MJO in southern summer, but it does not necessarily follow that every MJO, or even most of the MJOs, in southern summer will be accompanied by a modulation of the SPCZ. Because of this, we have examined MJOs using 10 years of the OLR data (1979-88) described in section 2. It is found that virtually all MJOs in southern summer exhibit an enhancement or an excitation of the SPCZ, with convection developing along the SPCZ simultaneously with, or slightly lagging, the intraseasonal convective anomalies over Indonesia. As suggested in the previous statement, in some cases there was pre-existing convection along the SPCZ, and the MJO signal was an enhancement of that convection; in other cases there was no prior SPCZ activity, and SPCZ convection appeared to be excited by the passage of the MJO.

The mechanism is symmetric about the equator, in that the situation is reversed in northern summer, with both the highest SSTs and the eastward propagating intraseasonal convective anomalies lying to the north of the equator. Hence a northeastward propagation of intraseasonal convective anomalies from Indonesia may be anticipated. Indeed, virtually all the 15 northeastward developing MJOs of Wang and Rui (1990) occurred in northern summer. However, this pattern of northeastward propagation over the western Pacific in northern summer is not as well developed as the southeastward propagation over the SPCZ in southern summer, and the postulated mechanism does not appear to be as important. Composite studies of northern summer MJOs show some evidence of northeastward development of convection (or, at least, negative OLR anomalies) over the western Pacific (Knutson and Weickmann 1987), but this tends to be at the same longitude as the upper tropospheric trough, rather than to the east of the trough as required by the proposed mechanism.

It is consistent with the hypothesis that the MJO only begins to have a poleward propagation component when the anomalous convection reaches Indonesia. Even in the particularly strong MJO of March-April 1988, there was always some "residual" convec- 
tion over the Indonesian region, such that when the anomalous "intraseasonal" convection was over Africa, its associated tropical circulation anomalies over the Indian Ocean would tend to be countered by the circulation associated with the "residual" convection. It is only when the "intraseasonal" convection reaches Indonesia, and is in phase with the "residual" convection there, that there can be an equatorward advection of high PV to the east, and the subsequent poleward and eastward development of convection. In the case study, convection continued to develop eastwards along the equator as well as developing southeastwards along the SPCZ (Fig. 1). A scenario could be envisaged where the convection propagates eastward along the equator by a moist Kelvin wave or other mechanism, and forces a NW-SE aligned band of "SPCZ" convection to the southeast. This whole structure, with both an equatorial part and a forced subtropical part, then moves eastward.

The mechanism appears to be robust to reasonable changes in the model parameters. The position and spatial structure of the subtropical response were reproduced for a range of heating functions and basic states. The magnitude of the subtropical response was rather weakly dependent on the relative proximity of the "Indonesian" convection to the large PV gradients associated with the subtropical jet. To interact with each other, the distance between them must be at most the meridional scale of the upper tropospheric anticyclone, about $25^{\circ}$. Such conditions are most likely to be met in southern summer, when convection is at its most southward latitude. Indeed, as described above, interaction between the MJO and the SPCZ is at its strongest in southern summer. It was noted earlier that, if the convection and large PV gradients were separated by slightly more than about $25^{\circ}$ latitude, then an interaction between the two could still occur, if the convection remained at the same longitude for a few days, rather than propagating away eastwards along the equator. Such a "stalling" of the MJO convection at Indonesian longitudes has indeed been observed (e.g., Hsu et al 1990; Weickmann and Khalsa 1990).

The induced ascent mechanism may also have relevance for the existence of the mean SPCZ itself, as mean Indonesian convection will force mean ascent over the SPCZ region which could force mean convection there. In particular, the imposed diabatic heating representative of 26 March 1988 (Fig. 11a) is rather similar in shape to that of the mean diabatic heating over Indonesia, and this heating configuration was able to force ascent over the SPCZ region, even from a zonally symmetric basic state (i.e. with no initial SPCZ structure present). This mechanism has previously been suggested by Webster (1981), who used a two level model with a climatological basic state. Initially, an SST anomaly on the equator forced a direct response. The vertical velocity of this direct response was allowed to feed back onto the circulation by an amplification factor, and a steady state solution was produced iteratively, that included ascent polewards and eastwards of the equatorial SST anomaly. Similarly, as suggested by Hoskins (1991), the northern hemisphere summer mid-Pacific trough may be due to equatorward advection of PV on the eastern flank of the Asian monsoon anticyclone. However, as the intraseasonal variability of the SPCZ is of the same order of magnitude as the mean SPCZ, a significant contribution to the "mean" SPCZ will actually come from the excitation of the SPCZ during the passage of MJOs. Hence it may actually be somewhat misleading to talk of a mean SPCZ.

\section{ACKNOWLEDGEMENT}

The AVHRR data was courtesy of Harry Hendon and Ken Sperber.

\section{REFERENCES}


Ardanuy, P. E. and Arkin, P. A. 1989

Emanuel, K. A.

Gill, A. E.

Heckley, W. A. and Gill, A. E.

Hoskins, B. J.

Hoskins, B. J., Hsu, H.- H., James, I. N., Masutani, M., Sardeshmukh, P. D. and

White, G. H.

Hoskins, B. J. and Karoly, D.

Hoskins, B. J. and

Simmons, A. J.

Hsu, H. -H., Hoskins, B. J. and

Jin, F. -F.

Jin, F. -F. and Hoskins, B. J.

$\mathrm{Ju}, \mathrm{J}$. and Slingo, J. M.

Kiladis, G. N., von Storch, H. and van Loon, $\mathrm{H}$.

Knutson, T. R. and

Weickmann, K. M.

Kodama, Y. -M.

Lau, K. -M. and Peng, L.

Matthews, A. J.

Nastula J., Gambis, D. and Feissel, M.

Neelin, J. D., Held, I. M. and

Cook, K. H.

Rodwell M. J. and

Hoskins, B. J.

Rui H. and Wang, B.

Vincent, D. G.

Wang B. and Rui, H.

Webster, P. J.

Webster, P. J.

Weickmann, K. M. and

Khalsa, S. J. S.
Estimating climatic-scale precipitation from space: A review. J. Climate., 2, 1229-1238

1987 An air-sea interaction model of intraseasonal oscillations in the tropics. J. Atmos. Sci., 44, 2324-2340

1980 Some simple solutions for heat induced tropical circulations. Q.J.R. Meteorol. Soc., 106, 447-462

1984 Some simple analytical solutions to the problem of the forced equatorial long waves. Q.J.R. Meteorol. Soc., 110, 203-217

1991 Towards a PV- $\theta$ view of the general circulation. Tellus, 43, $27-35$

1989 Diagnostics of the global atmospheric circulation based on ECMWF analyses 1979-1989. WMO, TD-No. 326

1981 The steady linear response of a spherical atmosphere to thermal and orographic forcing. J. Atmos. Sci., 38, 11791196

1975 A multi-layer spectral model and the semi-implicit method. Q.J.R. Meteorol. Soc., 101, 637-655

1990 The 1985/86 intraseasonal oscillation and the role of the extratropics. J. Atmos. Sci., 47, 823-839

1995 The direct response to tropical heating in a baroclinic atmosphere. J. Atmos. Sci., 52, 307-319

1995 The Asian summer monsoon and ENSO. Q.J.R. Meteorol. Soc., 122, 1133-1168

1989 Origin of the South Pacific convergence zone. J. Climate, 2, 1185-1195

1987 30-60 day atmospheric oscillations: composite life cycles of convection and circulation anomalies. Mon. Weather Rev., 115, 1407-1436

1993 Large-scale common features of sub-tropical convergence zones (the Baiu Frontal Zone, the SPCZ, and the SACZ). Part II: Conditions of the circulations for generating the STCZs. J. Meteorol. Soc. Japan, 71, 581-610

1987 Origin of low frequency (intraseasonal) oscillations in the tropical atmosphere. Part I: Basic theory. J. Atmos. Sci., 44, 950-972

1993 The intraseasonal oscillation. Ph.D. thesis. University of Reading

1990 Correlated high frequency variations in polar motion and length of the day in early 1988. Ann. Geophys., 8, 565-570

1987 Evaporation-wind feedback and low frequency variability in the tropical atmosphere. J. Atmos. Sci., 44, 2341-2348

1996 Monsoons and the dynamics of deserts. Q.J.R. Meteorol. Soc., 122, 1385-1404

1990 Development characteristics and dynamic structure of tropical intraseasonal convection anomalies. J. Atmos. Sci., 47, 357-379

1994 The South Pacific convergence zone (SPCZ): A review. Mon. Weather Rev., 122, 1949-1970

1990 Synoptic climatology of transient tropical intraseasonal convection anomalies: 1975-1985. Meteorol. Atmos. Phys., 44, 43-61

1981 Mechanisms determining the atmospheric response to sea surface temperature anomalies. J. Atmos. Sci., 38, 554571

1983 Mechanisms of monsoon low frequency variability: Surface hydrological effects. J. Atmos. Sci., 40, 2110-2124

1990 The shift of convection from the Indian Ocean to the western Pacific Ocean during a 30-60 day oscillation. Mon. Weather Rev., 118, 964-978 
Weickmann, K. M.,

Lussky, G. R. and

Kutzbach, J. E.
1985 Intraseasonal (30-60 day) fluctuations of outgoing longwave radiation and $250 \mathrm{mb}$ streamfunction during northern winter. Mon. Weather Rev., 113, 941-961 


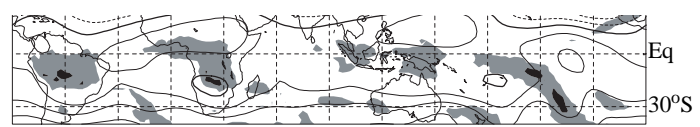

12 March 88

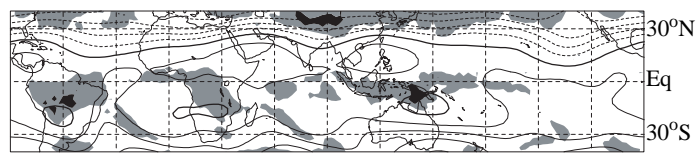

17 March 88

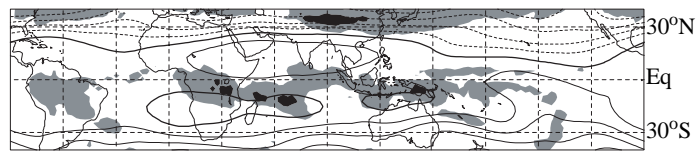

22 March 88

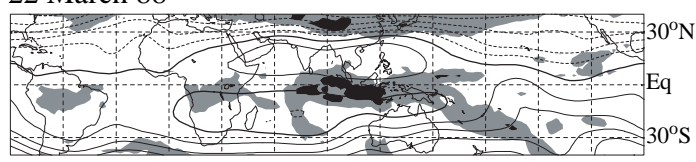

27 March 88

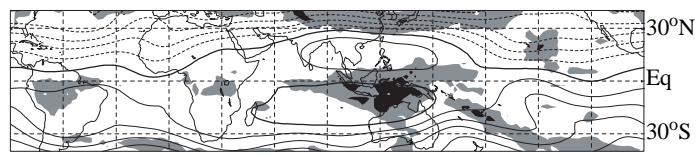

1 April 88
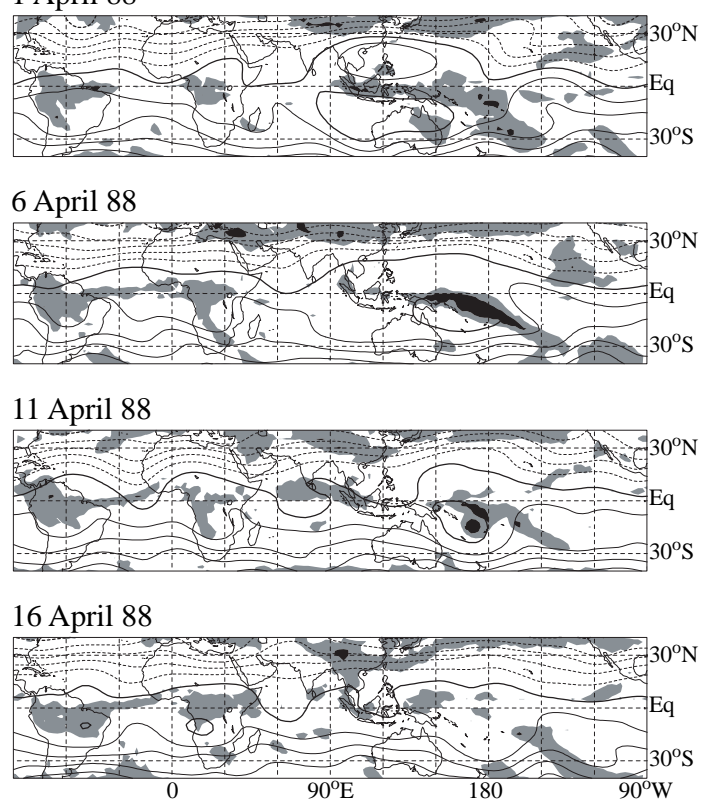

Figure 1. Pentad mean OLR and 355K streamfunction for the period 5 March - 18 April 1988. The date indicates the middle day of the pentad. OLR is shaded (darkly) below the 225 (175) $\mathrm{W} \mathrm{m}^{-2}$ level. Streamfunction contours are every $2 \times 10^{7} \mathrm{~m}^{2} \mathrm{~s}^{-1}$; positive (negative) contours are solid (dashed) and the zero contour is in bold. 
(a)

26 March 88

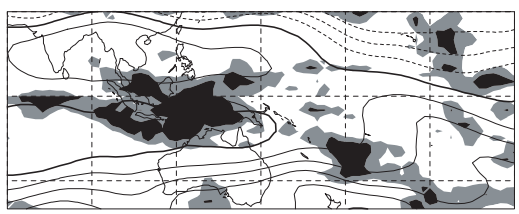

27 March 88

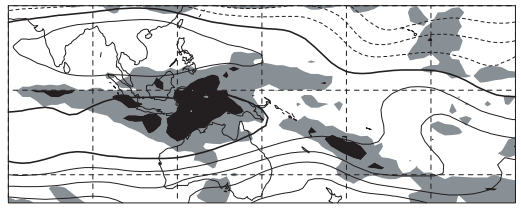

28 March 88

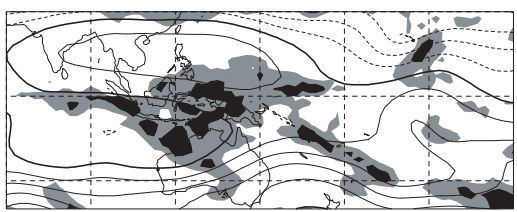

29 March 88

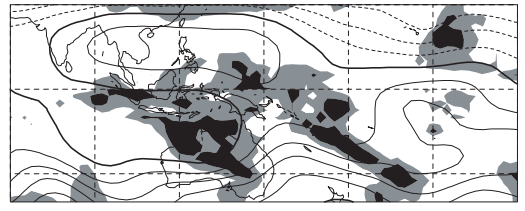

30 March 88

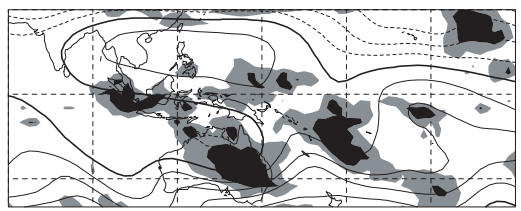

31 March 88

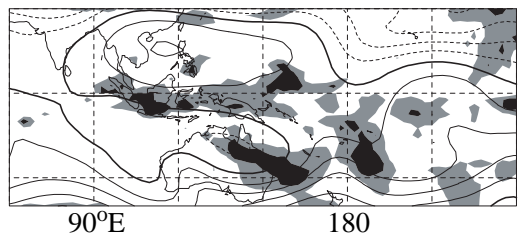

(b)

26 March 88

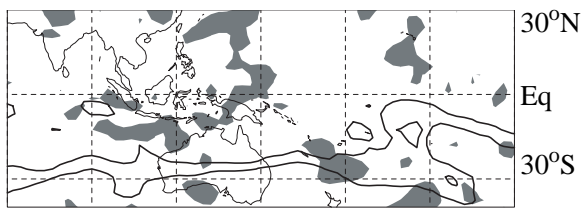

27 March 88

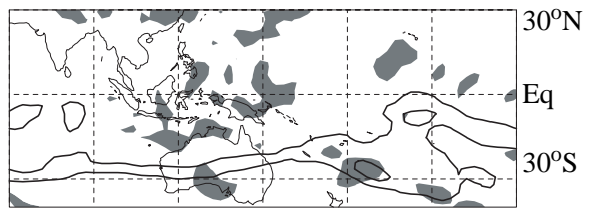

28 March 88

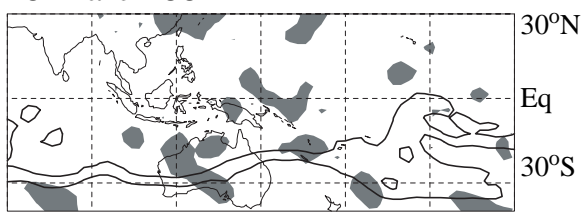

29 March 88

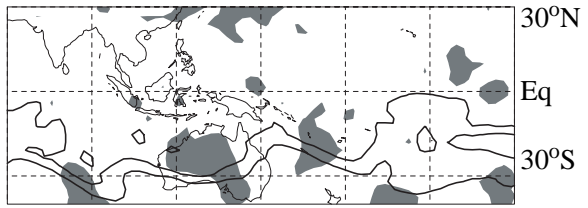

30 March 88

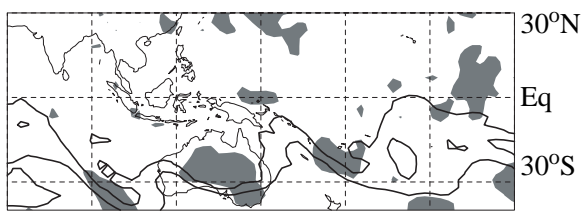

31 March 88

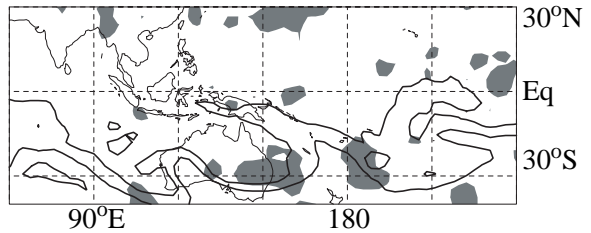

Figure 2. (a) Daily mean OLR and 355K streamfunction for the period $26-31$ March 1988. OLR is shaded (darkly) below the $225(175) \mathrm{W} \mathrm{m}^{-2}$ level. Streamfunction contours are every $2 \times 10^{7} \mathrm{~m}^{2}$ $\mathrm{s}^{-1}$; positive (negative) contours are solid (dashed) and the zero contour is in bold. (b) $355 \mathrm{~K}$ potential vorticity and $500 \mathrm{mb}$ omega for the same days. Potential vorticity contours (bold) are -2 and -0.5 PVU . Omega is shaded below $-2.5 \mathrm{mb} \mathrm{hr}^{-1}$ (ascent). 


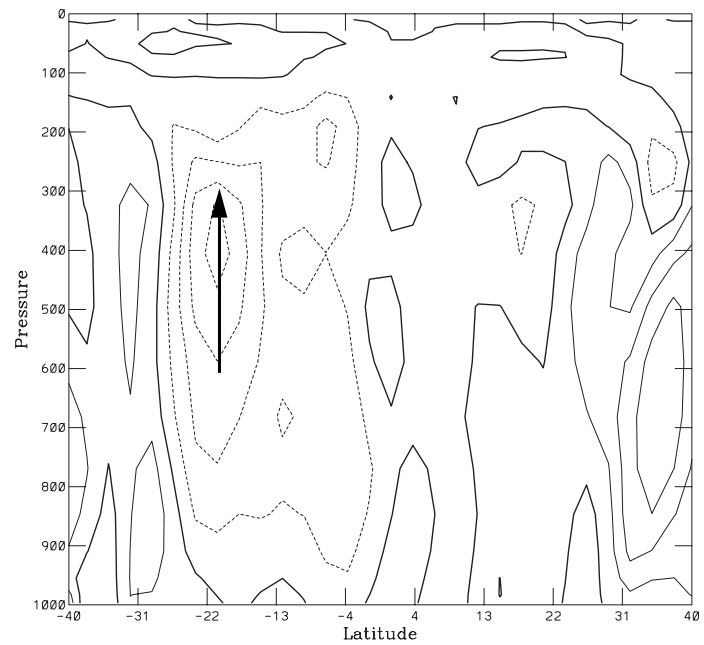

Figure 3. Vertical section of omega at $170^{\circ} \mathrm{E}$ on 29 March 1988. Contours are every $2 \mathrm{mb} \mathrm{hr}^{-1}$, with dashed contours (and arrow) indicating ascent.

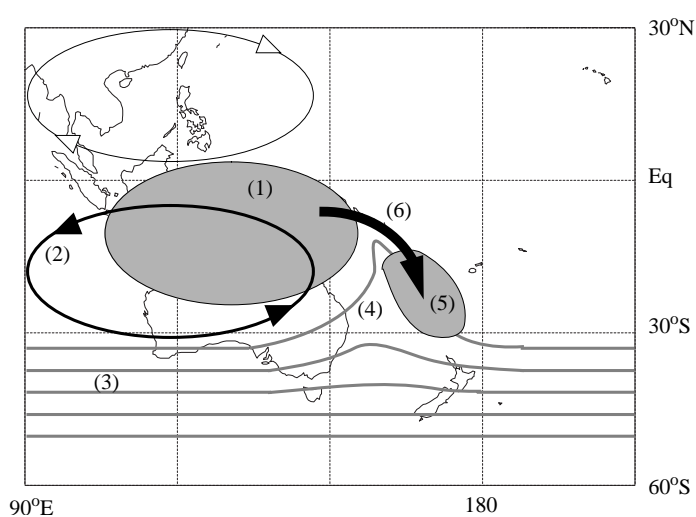

Figure 4. Schematic of hypothesised mechanism for the development of convection along the SPCZ during an MJO. Convection over Indonesia (1) associated with the passage of a MJO leads to an upper tropospheric anticylone (2). Poleward of the anticyclone, there is a large PV gradient, associated with the subtropical jet and the tropopause (3). Equatorward advection of "high" PV air on the eastern flank of the anticylone leads to an upper tropospheric trough (4), which induces deep ascent to the east (5). This region of deep ascent, to the southeast of Indonesia, is over the SPCZ, an area susceptible to deep convection. Hence strongly enhanced convection can be triggered by the deep ascent and convection develops from Indonesia into the SPCZ (6).

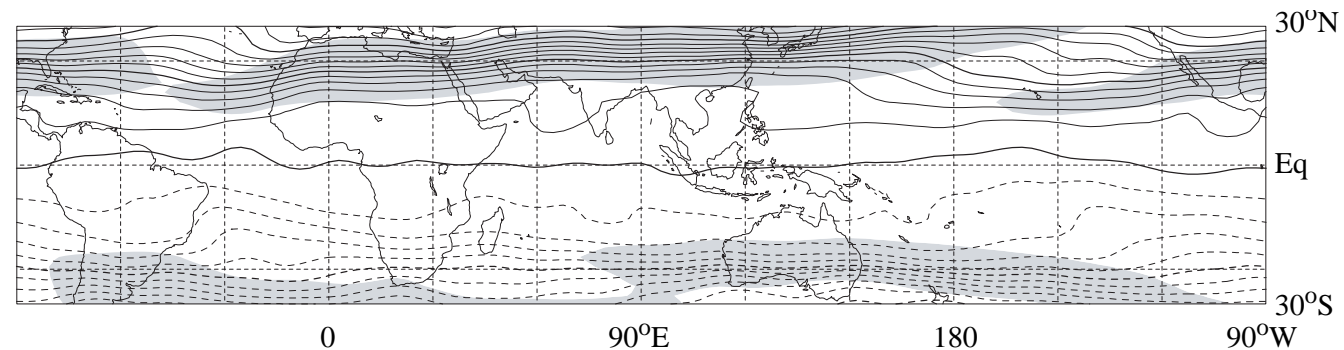

Figure 5. Climatological basic state (MAM 1983-89). 355K potential vorticity. Contour interval is 0.5 PVU; positive (negative) contours are solid (dashed) and the zero contour is in bold. Shaded regions have $355 \mathrm{~K}$ zonal wind greater than $25 \mathrm{~m} \mathrm{~s}^{-1}$. 


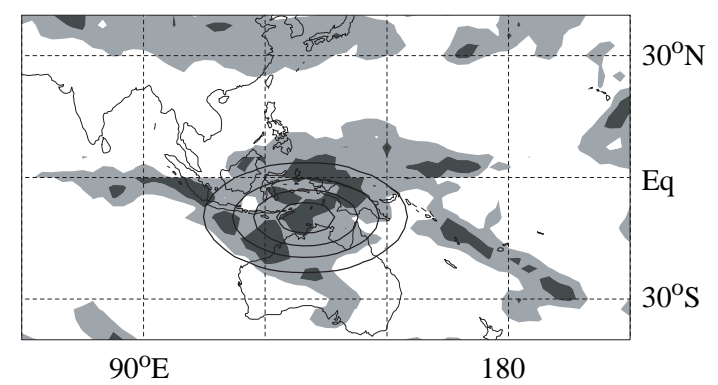

Figure 6. Idealised heating shape, together with the OLR field of 28 March 1988, shaded (darkly) below $225(175) \mathrm{W} \mathrm{m}^{-2}$.

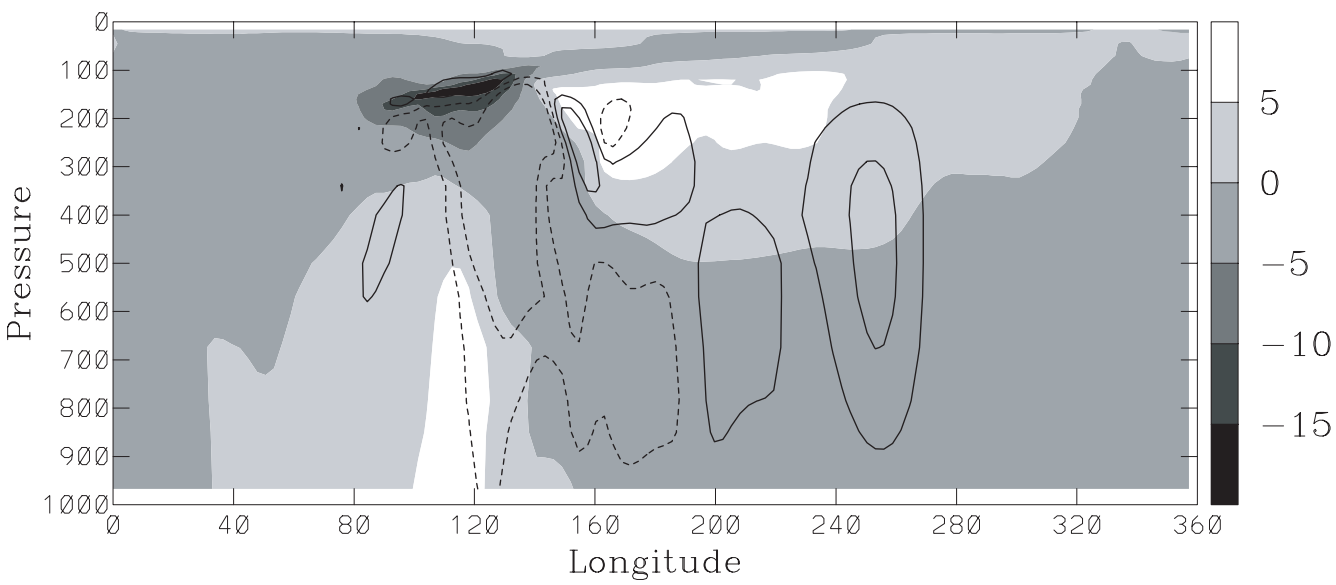

Figure 7. Longitude-height section of perturbation zonal wind and omega along the equator on day 3 of the integration. Zonal wind is shaded every $5 \mathrm{~m} \mathrm{~s}^{-1}$ (easterlies are shaded darkly). Only the 0.3 and $1 \mathrm{mb} \mathrm{hr}^{-1}$ omega contours are shown. Dashed (solid) contours indicate ascent (descent). The prescribed heating is centred at $130^{\circ} \mathrm{E}$, and Kelvin wavefronts are evident at $170^{\circ} \mathrm{E}, 210^{\circ} \mathrm{E}$ and $255^{\circ} \mathrm{E}$.
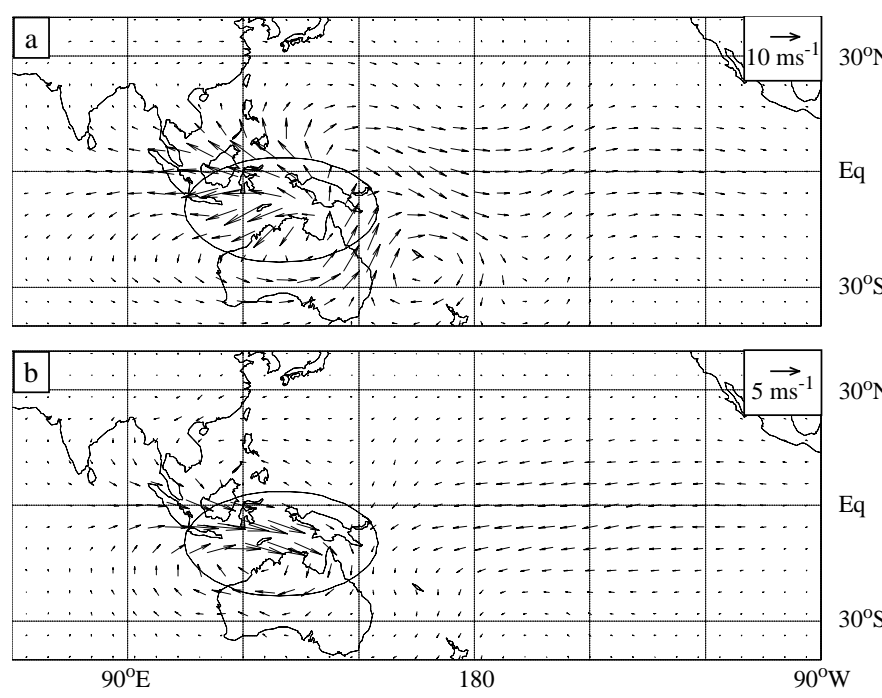

Figure 8. Perturbation wind vectors at (a) $150 \mathrm{mb}$, and (b) $850 \mathrm{mb}$ on day 3 of the integration. The heating region is outlined. 

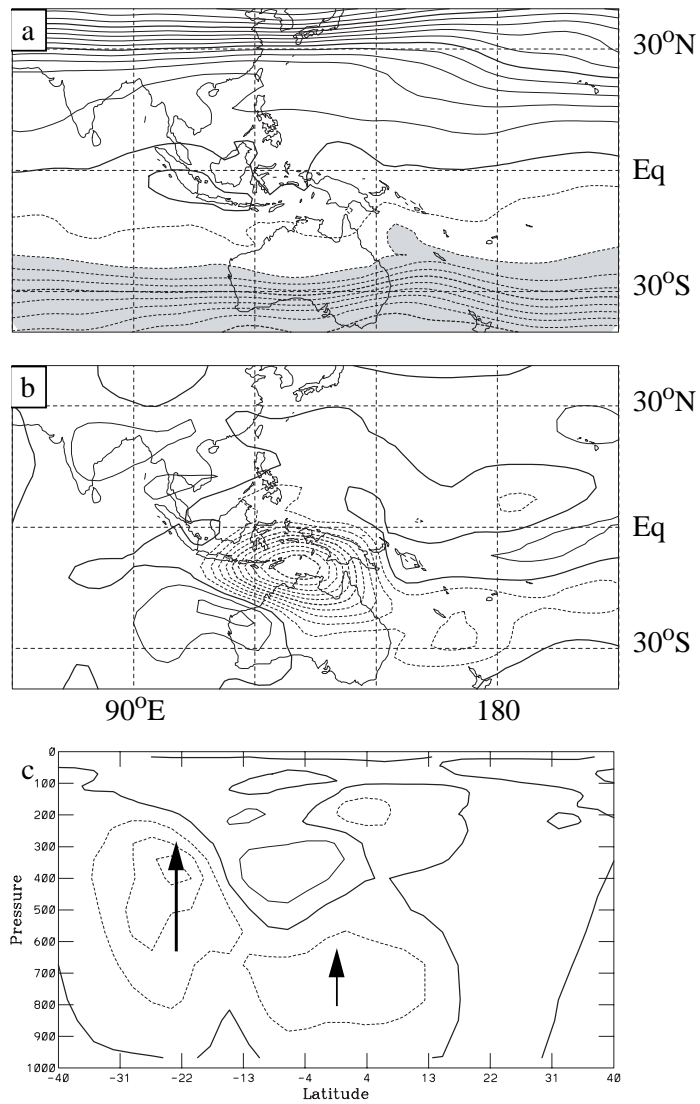

Figure 9. (a) Total potential vorticity at $355 \mathrm{~K}$, shaded below -1 PVU, (b) perturbation omega at $500 \mathrm{mb}$, and (c) vertical section of perturbation omega at $170^{\circ} \mathrm{E}$ (arrows indicate ascent), on day 3 of the integration. Contour intervals are $0.5 \mathrm{PVU}, 0.5 \mathrm{mb} \mathrm{hr}^{-1}$, and $0.5 \mathrm{mb} \mathrm{hr}^{-1}$, respectively; positive (negative) contours are solid (dashed) and the zero contours are in bold.

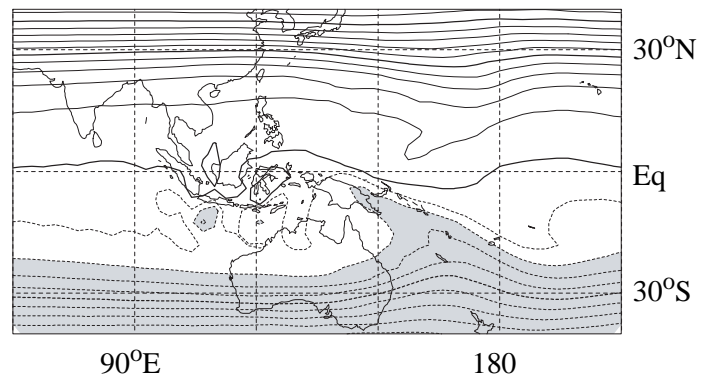

Figure 10. Total potential vorticity at $355 \mathrm{~K}$, on day 5 of the integration with an initial zonally symmetric MAM basic state. Contour interval is 1 PVU; positive (negative) contours are solid (dashed), the zero contour is in bold, and values below -1 PVU are shaded. 

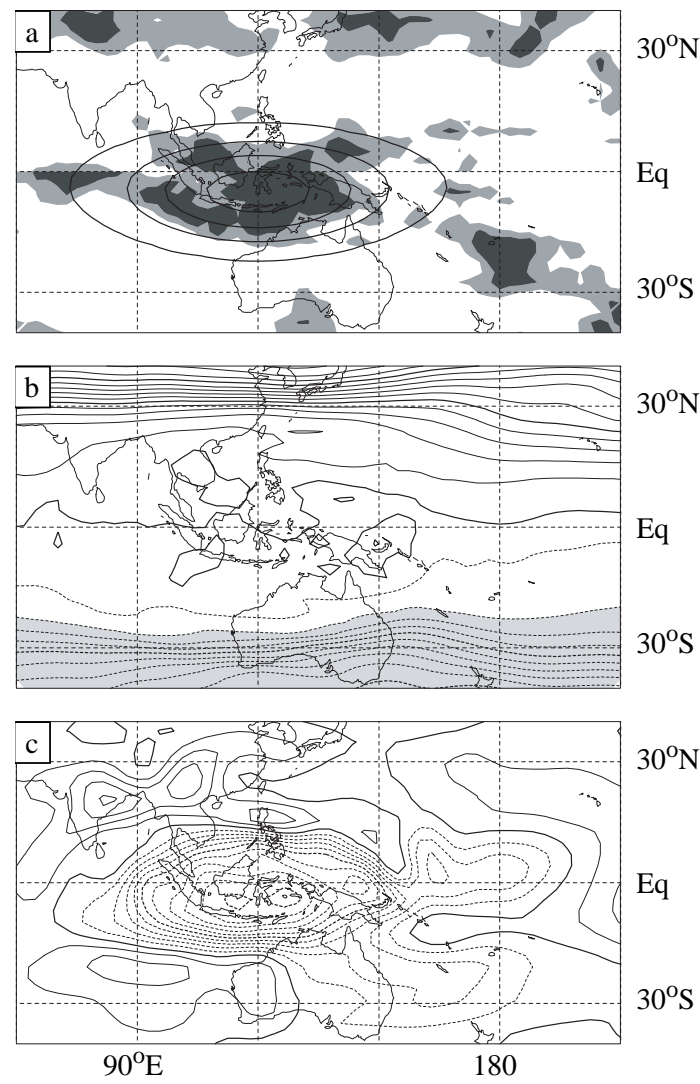

Figure 11. (a) Idealised heating shape, together with the OLR field of 26 March 1988, shaded (darkly) below 225 (175) $\mathrm{W} \mathrm{m}^{-2}$. (b) Total potential vorticity at $355 \mathrm{~K}$ (shaded below -1 PVU; contour interval is $0.5 \mathrm{PVU}$ ) and (c) perturbation omega at $500 \mathrm{mb}$ (contour interval is $0.5 \mathrm{mb} \mathrm{hr}^{-1}$ ), both on day 3 of the integration. Positive (negative) contours are solid (dashed) and the zero contour is in bold. 